\title{
Enrichment Activities in Support of a Student Integrated Intern Research Experience
}

\section{Dr. Manuel D. Rossetti, University of Arkansas}

MANUEL D. ROSSETTI is a Professor in the Industrial Engineering Department at the University of Arkansas. He received his Ph.D. in Industrial and Systems Engineering from The Ohio State University. His research and teaching interests are in the areas of simulation modeling, logistics optimization, and inventory analysis applied to manufacturing, distribution, and health-care systems. He serves as an Associate Editor for the International Journal of Modeling and Simulation and is active in IIE, INFORMS, and ASEE.

\section{Dr. Kim LaScola Needy, University of Arkansas}

Kim LaScola Needy is Department Head and 21st Century Professor of Industrial Engineering at the University of Arkansas. Prior to her academic appointment, she gained industrial experience while working at PPG Industries and Boeing. Her first faculty appointment was at the University of Pittsburgh. Dr. Needy's research interests include engineering management, engineering economic analysis and sustainable engineering. She is President of IIE as well as a member of ASEE, ASEM, APICS and SWE. She is a licensed P.E. in Kansas.

\section{Dr. Edgar C Clausen, University of Arkansas}

Dr. Clausen currently serves as Professor, Associate Department Head and the Ray C. Adam Endowed Chair in Chemical Engineering at the University of Arkansas. His research interests include bioprocess engineering, the production of energy and chemicals from biomass and waste, and enhancement of the K12 educational experience. Professor Clausen is a registered professional engineer in the state of Arkansas.

\section{Dr. Carol Schubert Gattis, University of Arkansas}

Carol Schubert Gattis is the Associate Dean of the Honors College and an Associate Professor of Industrial Engineering at the University of Arkansas. She received her B.S. and M.S. degrees in Electrical Engineering and her Ph.D. in Engineering from the University of Arkansas. Dr. Gattis' research areas include university student recruitment, retention and diversity, as well as professional development of middle school math and science teachers.

\section{Dr. Micah Hale, University of Arkansas}

Dr. Hale is a Professor of Civil Engineering at the University of Arkansas. His research interests include concrete materials and structural concrete. 


\title{
Enrichment Activities in Support of a Student Integrated Intern Research Experience
}

\begin{abstract}
A national need exists for increasing the number of United States citizens who complete engineering degrees. The Student Integrated Intern Research Experience (SIIRE) program at the University of Arkansas, now in its second year, provides financial support to students from all engineering departments within the College of Engineering. Through scholarships and integrated industry supported work experiences with on-campus research activities, SIIRE provides a pathway to a graduate engineering degree. Progress made in the first year of the SIIRE program will be discussed including the process used for the selection of the inaugural cohort of students. A set of activities designed to mentor and enrich the professional development of the SIIRE students will be described including summer work experience, research experience, professional development, faculty mentoring and peer mentoring. The professional development activities are designed to target specific points in the students' plan of study. They include various topics such as preparation of a personal development plan (sophomore level), resume writing and job search skills (sophomore and senior level), developing research skills (junior level), seven habits of highly effective people (senior level), writing and presenting an engineering-based business case (junior level), and presenting and communication research (M.S. level).
\end{abstract}

\section{Overview of the SIIRE Program}

The Student Integrated Intern Research Experience (SIIRE) program at the University of Arkansas is funded via the NSF S-STEM program. The NSF S-STEM program provides student scholarship funds to encourage and enable academically talented but financially needy students to complete STEM degrees and enter the workforce. The SIIRE project addresses NSF's programmatic goal by integrating external (industry supported) intern or co-op experiences of students with ongoing on-campus engineering research activities to provide a guided pathway to a graduate engineering degree. The requested scholarship funds defray student educational costs during their sophomore, junior, and senior years of undergraduate study and during 1.5 years of their graduate studies.

The SIIRE program addresses the following objectives:

1. To provide underrepresented and financially needy undergraduate students with information on the benefits and opportunities associated with graduate education,

2. To provide underrepresented and financially needy undergraduate students with enhanced financial support and career experiences to improve the likelihood of completing both a BS and a MS in engineering,

3. To provide personalized integrated industry and academic mentoring and professional development that results in increased enrollment and completion of graduate engineering degrees involving industry beneficial research,

4. To increase the number of highly skilled employees in engineering fields ready to directly apply engineering research, 
5. To develop an innovative program that integrates industry based student experiences with on campus research experiences that result in benefits to industry, faculty, and students.

These objectives are achieved via the following features 1) leveraged scholarship support for a cohort of students with financial need, 2) a cohort of students focused upon engineering strategic research initiatives, 3) integrated one-on-one faculty and industry joint mentoring, 4) industry motivated graduate research topics, 5) course work options enabling completion of B.S. and M.S. degrees in 5.5 total years, and 6) the seeding of highly trained practicing engineers within the workforce.

Details of this program at the University of Arkansas were described and presented at the 2013 ASEE conference. Rather than repeating these details, the reader is referred to this previous paper $^{1}$. In this follow-on paper, we describe progress made in the first year of the SIIRE program, including the process used for the selection of the inaugural cohort of students. Next, activities designed to mentor and enrich the professional development of the SIIRE students are presented. Finally, we conclude with some thoughts for future efforts within the program and suggestions on how the SIIRE program developed at the University of Arkansas can be readily adapted and implemented at other programs across the nation.

\section{Progress Made in Year 1}

In the first year of the program, a cohort of students needed to be recruited into the program. A decision was made by the program oversight team to focus predominantly on recruiting incoming sophomores (with perhaps a few juniors) into the program. We chose not to recruit seniors or masters degree students. During the Spring 2013 semester, all College of Engineering students (approximately 2,700 students) were contacted via email and handouts. The University of Arkansas College of Engineering has a common freshman engineering program (FEP). SIIRE students were initially recruited from the FEP during their second semester of study to enter the SIIRE program in their sophomore year. Freshman engineering students (809 students) were specifically targeted via classroom announcements. Freshman engineering students were given information about the SIIRE program and in addition, the program oversight team visited all freshman engineering students in their Freshman Seminar class to describe the SIIRE program and answer any questions. The SIIRE program was presented to the College of Engineering department heads so that they could relay the program information to appropriate faculty within each department involved with student advising. In addition, there is at least one faculty member from each of the eight engineering departments on the program oversight team and we relied on these individuals to market and recruit upperclassmen from their respective departments into the SIIRE program. As was indicated, in this first year, we limited our search of upperclassmen to students in their junior year.

SIIRE undergraduate students must meet the following criteria: 1) must be a US citizen, permanent resident, national or refugee eligible to receive NSF funds; 2) must receive a University of Arkansas renewable scholarship (minimum criteria 24+ ACT and 3.5+ HSGPA); 3) must have financial need, as determined by the federal government through Free Application for Federal Student Aid FAFSA submission; 3) must pursue a bachelor of science degree in engineering and be a full-time engineering student; 5) must demonstrate a work ethic, time 
management skills, communication skills and professionalism; and 6) must agree to participate in all parts of the program.

The application process required that students submit an application form showing that they met the SIIRE criteria identified above, a two-page essay, and two letters of recommendation from faculty. The program oversight team held a workshop prior to the submission due date to assist students in preparing their application process. During the time frame from March 1 to April 15th of 2013, we received a total of twenty-six applications for the SIIRE program. Students from all eight engineering departments (Biological (4 students), Biomedical (5 students), Chemical (6 students), Civil (1 student), Computer/Computer Science (1 student), Electrical (1 student), Industrial (4 students) and Mechanical (4 students)) were part of the applicant pool.

A subset of the program oversight team individually reviewed each applicant and rated them in one of three categories, (1) fund, (2) consider funding, and (3) do not fund. A "do not fund" rating was reserved predominantly for students who did not meet one or more criteria.

Typically, this was due to an inferior GPA or not meeting a mandatory NSF criteria (e.g. not a U.S. citizen). Of the twenty-six students, ten students were eliminated due to incomplete applications or for not meeting NSF program eligibility criteria. Of the sixteen applicants in the remaining pool there were ten applicants from underrepresented groups ( 8 women) .

A team meeting was held by the program oversight committee to collectively review the applicant pool. Once a group ranking was determined, we confirmed each student's financial need based on their Free Application for Federal Student Aid (FAFSA) application. In the end, there were four applicants who met all SIIRE criteria, except the financial need. Rather than excluding these student from the program outright, we consulted with each student to determine if they wished to participate in the SIIRE program without funding. Three of the four students elected to participate citing the various benefits of the program beyond the scholarship. This was a great achievement for a couple of reasons. First, the financial eligibility of students can change from year to year, thus students once financially eligible may find themselves not eligible in the future. We now have evidence that we may be able to retain these students without funding as a result of the value placed on the other various benefits of the program. Second, this allows us to expand the program to more students with our limited scholarship funds. In the future, we can challenge ourselves to find alternative, unrestricted sources of funding to award to students who by definition do not meet the financial need test.

In the end, the composition of the inaugural SIIRE class included 15 students with one to three students from each of the eight engineering departments. A total of 13 sophomores and 2 juniors were included in this cohort, with 6 women and 1 applicant of color. This class entered the SIIRE program in Fall 2013.

An integral component of the SIIRE program and one of the reasons we decided to accept a large sophomore class is the program enrichment activities designed for a cohort of students. The next section describes these activities. 


\section{Enrichment Activities}

SIIRE students have a number of specifically designed activities to enrich their academic experience as illustrated in Table 1. These activities include summer work experience, research experience, professional development, faculty mentoring and peer mentoring. These activities vary across the student's plan of study and are targeted to meet the specific needs of the SIIRE program.

Table 1 - Enrichment Activities

\begin{tabular}{|c|l|l|l|l|l|}
\hline & \multicolumn{1}{|c|}{ Sophomore } & \multicolumn{1}{|c|}{ Junior } & \multicolumn{1}{|c|}{ Senior } & MS Year 1 & MS Year 2 \\
\hline $\begin{array}{c}\text { Work } \\
\text { Experience } \\
\text { (summer) }\end{array}$ & $\begin{array}{l}\text { Optional Co-Op } \\
\text { or Internship } \\
\text { Optional Co-Op } \\
\text { or internship }\end{array}$ & $\begin{array}{l}\text { Required Co- } \\
\text { Op or internship }\end{array}$ & $\begin{array}{l}\text { Required Co- } \\
\text { op/internship on } \\
\text { graduate } \\
\text { research }\end{array}$ & \\
\hline $\begin{array}{c}\text { Research } \\
\text { Experience }\end{array}$ & Optional & Optional & Required & $\begin{array}{l}\text { Prepare MS } \\
\text { thesis proposal }\end{array}$ & Defend MS thesis \\
\hline $\begin{array}{c}\text { Professional } \\
\text { Development }\end{array}$ & Monthly meeting & $\begin{array}{l}\text { Meeting at least } \\
\text { twice a month }\end{array}$ & $\begin{array}{l}\text { Meeting at least } \\
\text { twice a month }\end{array}$ & $\begin{array}{l}\text { Meeting at least } \\
\text { once per week }\end{array}$ & $\begin{array}{l}\text { Meeting at least } \\
\text { once per week }\end{array}$ \\
\hline $\begin{array}{c}\text { Faculty } \\
\text { Mentoring }\end{array}$ & \multicolumn{5}{|c|}{ As needed, at least once per semester } \\
\hline $\begin{array}{c}\text { Peer } \\
\text { Mentoring }\end{array}$ & \multicolumn{5}{|c|}{ Various (See Table 2) } \\
\hline
\end{tabular}

In this first phase of the SIIRE program, SIIRE scholars (who were predominantly sophomores) are matched with participating College of Engineering faculty who serve as their mentor. Students are expected to work with their faculty mentor to identify areas of interest and company internship or co-op opportunities. Peppas ${ }^{2}$ found that undergraduate students who participated in research experiences working directly with a faculty mentor were more likely to choose graduate school when compared with other students. The students also participate in professional development enrichment activities and are assisted in finding an optional co-op or internship for the summer between their sophomore and junior years. If the student participates in a co-op or internship during the summer, the student's faculty mentor is involved with reviewing the work experience, visiting the student "on the job," developing a relationship with the company, and assessing the potential for the student to develop research based on experience with the company.

Eleven different professional development activities have been designed by faculty and staff from across the College of Engineering targeted to specific points of study including three for sophomores, five for juniors, three for seniors and two for masters students. Two of the sessions developed are targeted at multiple cohorts such as juniors/seniors. Sessions vary in length from 1 to 4 hours, with most lasting 1 hour. The sessions are organized either in a seminar-like fashion, workshop or panel discussion. Table 2 describes each professional development activity, the topic of discussion, targeted group and includes an overview of the subject matter. 
Table 2 - Professional Development Activities

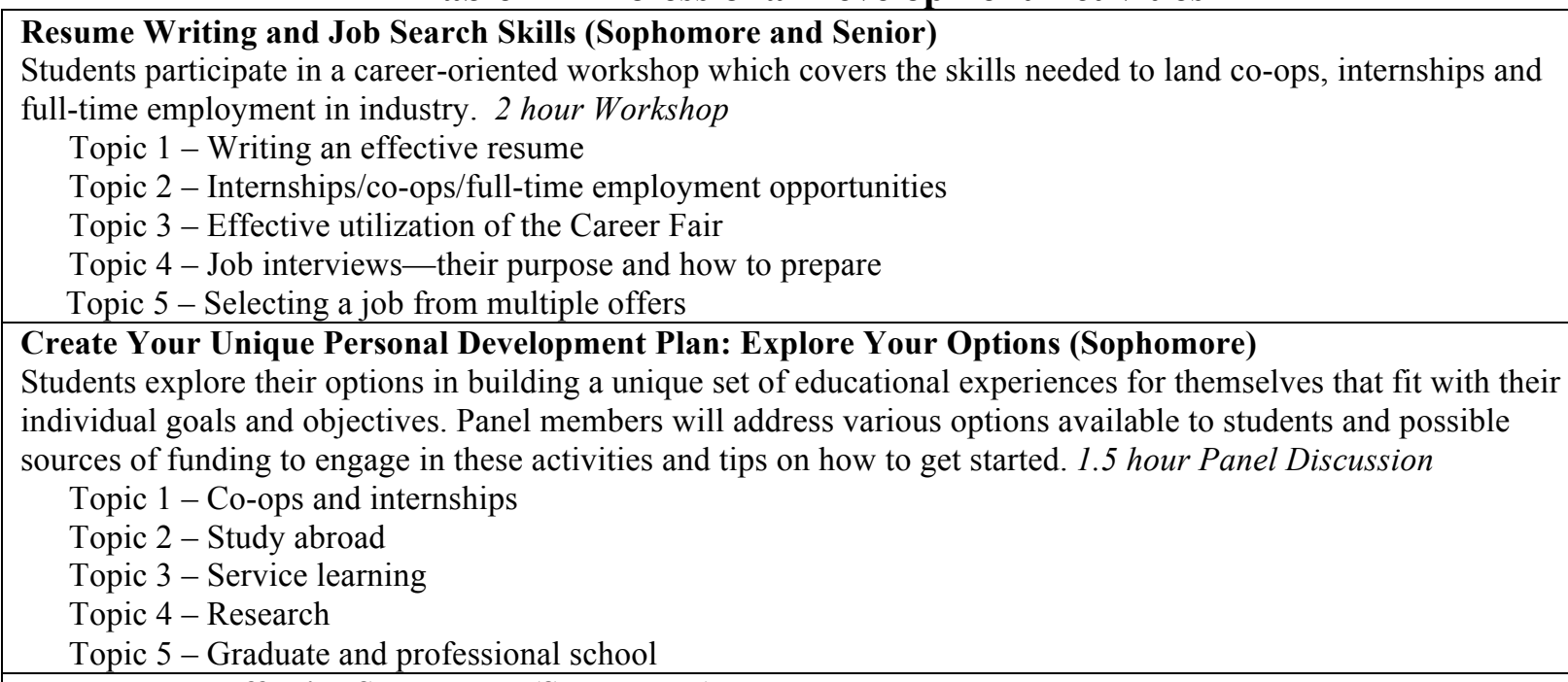

How to be an Effective Sophomore (Sophomore)

Students will engage in a workshop that helps them identify goals for their sophomore year. Group discussions will take place to not only assist students to determine their goals, but how to effectively manage them. 1 hour Workshop

Topic 1 - Academic and career goals

Topic 2 - Social goals

Topic 3 - Extracurricular goals

Topic 4 - Physical and Mental/Spiritual goals

Topic 5 - Financial goals

Effective Oral/Written Communication (Junior)

A typical comment from engineering students is that they won't have to write as professionals. This presentation will debunk that myth, and briefly introduce participants to typical genres and the major stylistic features of engineering writing. 1 hour Seminar

Topic 1 - Debunking the Myth: Engineering as a Writing Profession

Topic 2 - Genres of Writing in Engineering

Topic 3 - Engineering Style: Major Features

Developing Research Skills in Engineering and Science (Junior)

Students will be introduced to the skills necessary to become an independent researcher in science or engineering with a particular focus on the development of a research hypothesis and the assessment of research results. 1 hour Seminar

Topic $1-$ What is (and is not) research?

Topic 2 - Defining a research objective or hypothesis

Topic 3 - Finding and assessing the available literature

Topic 4 - Developing a strategy to address your research objective or hypothesis

Topic 5 - Documenting your research progress

Topic 6 - Critically assessing your research results

Writing and Presenting an Engineering-Based Business Case (Junior)

The purpose of engineering-based analyses is to form a recommendation for a future decision. This recommendation needs to be communicated in the context of an organization's business model. 4 hour Workshop

Topic 1 - Context for an engineering-based business case

Topic 2 - Decision making in organizations

Topic 3 - Example case study ("Mattson Foods: The Bardolini Division," HBR Case)

Topic 4 - Communication of a recommendation through the executive summary

Topic 5 - Executive summary for example case study

Topic 6 - Assignment case study (TBD)

Topic 7 - Participants work on assignment case study and executive summary

Topic 8 - Presentation and critique of assigned cases study executive summary 
Table 2 - Professional Development Activities (Continued)

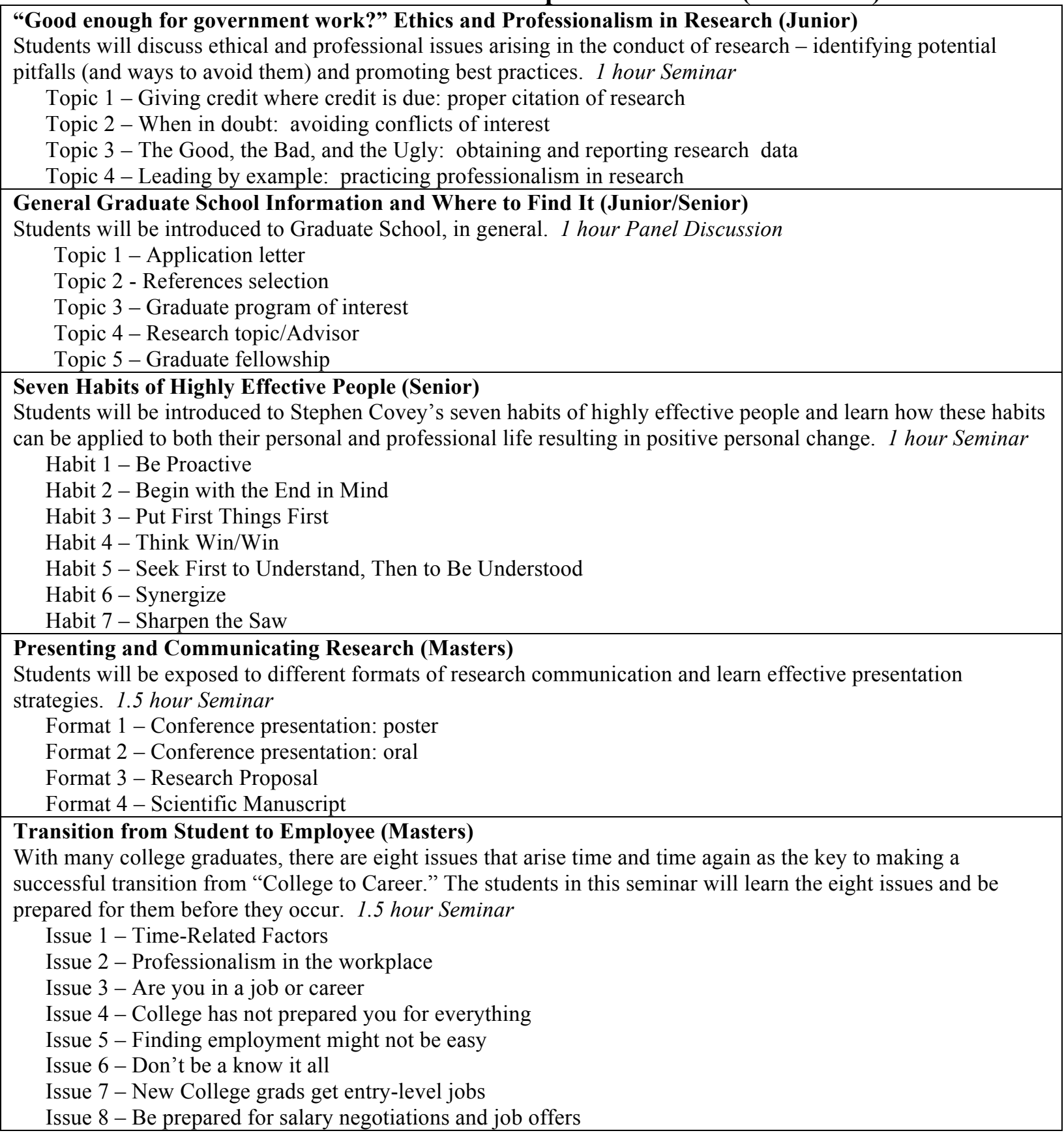

The first two professional development activities were held in Fall 2013. The first, Resume Writing and Job Search Skills, was led by the College of Engineering Director of Employer Relations. This was scheduled prior to the Fall STEM Career Fair held at the University of Arkansas and provided an opportunity for students to prepare for the career fair. For example, SIIRE students were required to bring their resumes with them and during the hands-on portion of the workshop, students met with faculty from the program oversight committee to receive feedback on their resumes. The Director of Employer Relations reviewed various topics with the 
students including the format of the career fair, how to dress, do's and don'ts of an interview, and other helpful topics.

The second professional development activity, Create Your Unique Personal Development Plan: Explore Your Options, was also held in Fall 2013 and led by the Associate Dean of the University of Arkansas Honors College. This session was set up as a panel discussion with a panelist addressing each of the five topics listed in Table 2. Students were required to submit in writing two-three questions in advance of the session and there were also provisions to submit questions at the session. After the formal portion of the presentation, a lively Q\&A session ensued.

Both sessions were held in the evening to avoid conflicts with students' class schedules and attendance was very strongly encouraged. Members from the faculty oversight committee attended the sessions as well. Plans are underway to schedule the third session, How to be an Effective Sophomore, in Spring 2014. So far, the feedback from the students has been mostly positive:

- $\quad$ The most beneficial part of SIIRE was having easy access to numerous faculty members to consult with about future opportunities such as internships. The SIIRE meetings have been relatively short and concise. They have been about topics that were all interesting and beneficial to me. I'm very thankful for this program and its resources in helping me further my career as a student.

- The resume workshop and the information about study abroad were very helpful, and helped clear up some questions I had about each. The presentation by the honors college at the last meeting was least beneficial to me because it did not apply to me. I wish there would have been an extra meeting right before the STEM fair to work on interview skills and things of that nature.

- $\quad$ The career planning seminar was extremely beneficial. I was able to get my resume reviewed and revised before the career fair. I do not have anything to complain about. The processing of the scholarship at the beginning of the semester took longer than I thought it would, but it ended up not being a big deal. This grant has enabled me to focus on my studies more because I have to work less. It has taken a lot of stress off of my shoulders. So Ijust want to say thank you.

- The workshops deemed extremely helpful. Especially the most recent meeting with the panel of faculty members that were there to present and answer any question I may have had. Although all of SIIRE has been great, the least beneficial factor would have to be the lack of meetings. I would personally enjoy having more meeting with more panels such as the one in the most recent meeting.

- I thoroughly enjoyed the workshops and all the useful information. I also loved getting to know professors within and outside of my own profession. All the information and preparation offered through SIIRE has been an encouraging and helpful experience. I have no memories of non-beneficial material. I am so thankful for the SIIRE program. It not only 
enables me to be a better student with less financial to worry about, it is also preparing me to be a better employee and mentor to other engineering students in engineering.

\section{Summary and Future Work}

This paper describes the SIIRE program at the University of Arkansas and shares progress made in the first year of the program with a focus on selection of the inaugural cohort of SIIRE scholars, and a description of professional development activities designed to enrich the students' academic experience. Good progress has been made thus far with an initial cohort of 15 students representing all eight engineering departments. Two professional development activities have been conducted and a third will be held in Spring 2014. To date, all SIIRE scholars have been retained and plans are underway to recruit the second cohort of students.

SIIRE addresses the national need for increasing the number of U.S. citizens who complete engineering degrees through an innovative use of company sponsored work experiences and professional development activities that may improve the way that students and faculty interact with industry. The experiences may also increase the likelihood that industry will better value engineers with M.S. degrees. The program will advance the knowledge of how to integrate cooperative education with graduate research. The program advances the discovery and dissemination of research that bridges undergraduate experiences with the attainment of graduate engineering degrees and strengthens industry partnerships for developing highly trained workforces.

The program as described in this paper can be implemented in other engineering programs with very little modification. It simply would take resources in the form of faculty and staff participation, student scholarships and industry participation. For more information on the structure of the program, please see reference [1]. We believe that a program such as this would resonate well with alumni and employers with whom universities have established partnerships as it provides a win-win program.

Future papers will present results from the program including assessment results involving a mixture of evaluation techniques, using implementation, progress and summative evaluative techniques. The evaluation will consist of both assessment of the various outcomes associated with the program goals as well as an overall evaluation of the students who participate in the program. Evaluation activities will be guided by evaluation questions that encompass the overarching vision of SIIRE, its content goals and objectives. The evaluation will examine whether students who participate in the SIIRE program become more interested in engineering; and be more attuned to engineering research.

\section{Acknowledgements}

This material is based upon work supported by the National Science Foundation under Grant No. 1154146. Any opinions, findings, and conclusions or recommendations expressed in this material are those of the author(s) and do not necessarily reflect the views of the National Science Foundation. 


\section{Bibliography}

1. Rossetti, M. Clausen, E., Gattis, C. S., Hale, M., \& Needy, K. L. (2013) On the development of a student integrated intern research experience as a pathway to graduate studies. 2013 American Society for Engineering Education Annual Conference Proceedings. Atlanta, GA.

2. Peppas, Nicholas A. "Student Preparation for Graduate School Through Undergraduate Research." Chemical Engineering Education, V15 (3), pp135-137, Summer, 1981. 